\title{
Preparation, Surface Characterization and Anticorrosive Behavior of Polyaniline and Poly (3,4-ethylenedioxythiophene) Deposited on Aluminum Alloy AA2024-T3 ${ }^{1}$
}

\author{
J. I. Iribarren ${ }^{a, b, *}$, M. Catalàa ${ }^{a}$ A. J. Conchello ${ }^{a}$, M. M. Pérez-Madrigal ${ }^{a, b}$, and C. Alemán ${ }^{a, b, * *}$ \\ ${ }^{a}$ Departament d'Enginyeria Química, EEBE, Universitat Politècnica de Catalunya, Campus Diagonal Besós, \\ Barcelona, 08019 Spain \\ ${ }^{b}$ Barcelona Research Center in Multiscale and Engineering, Universitat Politècnica de Catalunya, \\ Campus Diagonal Besós, Barcelona, 08019 Spain \\ *e-mail:jose.iribarren@upc.edu \\ **e-mail:carlos.aleman@upc.edu \\ Received May 31, 2017
}

\begin{abstract}
This work is focused on studying the preparation and characterization of two different conducting polymers, polyaniline and poly(3,4-ethylenedioxythiophene), on aluminum alloy AA2024-T3. In addition to the direct electrochemical deposition of the conducting polymers onto an untreated aluminum substrate, the alloy surface pre-treatments based on single chemical acid pickling or chemical acid pickling followed by application of self-assembled monolayers have been also considered before the coating application. Coatings electrochemically deposited onto both untreated and pre-treated substrates have been characterized by physicochemical and electrochemical techniques, whereas their protective performance has been evaluated by means of polarization electrochemical techniques and accelerated corrosion tests. Although conducting polymers are widely used as protective coatings for steel substrates, the results obtained in this work indicate that their protective effect is not improved when deposited onto aluminum.
\end{abstract}

Keywords: conducting polymers, aluminum protection, surface pre-treatments, steel protection, anticorrosive properties

DOI: $10.3103 / \mathrm{S} 1068375518030067$

\section{INTRODUCTION}

Aluminum is the third element found in the earth's crust. In its natural state, it is a very reactive metal and never occurs in the free-state in nature, owing to its great affinity for oxygen (i.e. aluminum and oxygen combine forming oxides or hydroxides). During the 20th century, aluminum outballanced copper in applications, currently being very close to iron.

Because of its properties, aluminum offers responses to the demand of specific applications by the alloy type selection, thermic treatments or fabrication processes. Between the most characteristic properties of aluminum and its alloys, the following deserve special attention: lightness, availability in a wide range of strength values, high strength to weight ratio, excellent conductivity of heat and electricity, highly reflective, non-ferromagnetism, non-pyrophoric and non-toxic behaviors. In the majority of service conditions, the corrosion resistance of aluminum alloys is good because a spontaneous passivation process of the surface occurs in numerous environments, the effi-

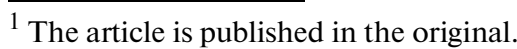

cacy of this passivation being improved by means of electrochemical treatments named anodization processes [1].

The alloy AA2024-T3 is a member of 2000 series of aluminum alloys, containing copper as its main alloying element $(3.8-4.9 \% \mathrm{w} / \mathrm{w})$, even though other elements as magnesium, iron and manganese are also present in its composition. It can be used for high strength structural applications and its machinability is excellent in the T-tempers with a fair workability and corrosion resistance. Thus, the mechanic strength of this alloy, which is frequently, achieved by a lamination based transformation process, enables applications as, for example, the fuselage skin in aerospace industry. Nevertheless, the improved mechanical behavior obtained from hardening through copper content is also the origin of a poor resistance against corrosion. This drawback is mainly caused by the galvanic coupling between copper and aluminum, which results in changes of the alloy microstructure. Thus, the formation and segregation of the intermetallic compounds, which can be placed in the grain boundaries, provoke several forms of microstructural corro- 


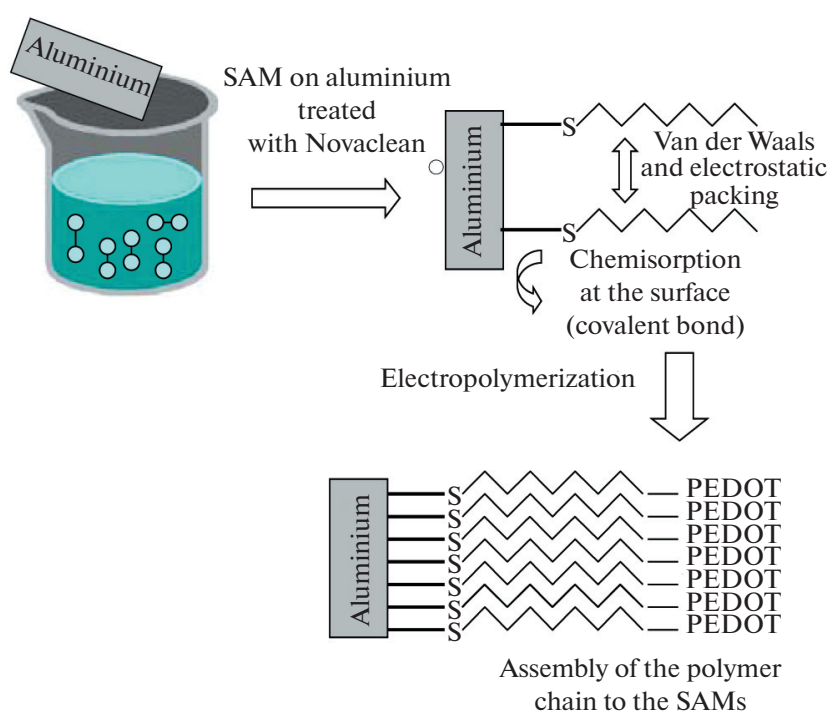

Scheme 1. Formation of SAMs of alkanethiols on surface and subsequent electropolymerization.

sion; (i.e. poultice, filiform, exfoliation and intergranular corrosion) [2].

In order to improve the resistance against corrosion, aluminum and aluminum alloys, for example, AA2024-T3, are anodized in an acid electrolyte (usually sulfuric acid) [3]. In addition to dyeing and sealing processes following anodization, some inhibitors, as $\mathrm{Cr}$ (VI) derivatives, can be incorporated to enhance the performance of the anodic film [4]. However, the use of $\mathrm{Cr}(\mathrm{VI})$ is forbidden in the EU and the USA due to its carcinogenic effects on human organism and its ability to generate toxic residues that, are very dangerous for the environment. Alternative inhibitors are being currently investigated to substitute $\mathrm{Cr}$ (VI), as for example vanadates, molybdates and permanganates based solutions [5-7].

In the past years, research has been focused on the development of non-chromate environmen-tallyfriendly organic compounds that can be coupled to conventional organic coatings. Usually, these inhibitors are directly applied onto the metal surface acting as the first organic barrier, while the conventional organic resin, which is applied onto such organic compound, behaves as a primer. The successful implementation of bi-coating largely depends on the previous surface preparation. In fact, in $80 \%$ of cases, failures in anticorrosion coatings are directly associated to a deficient surface preparation.

In this work, we propose two different conducting polymers (CPs): polyaniline (PAni) and poly $(3,4-$ ethylenedioxythiophene) (PEDOT), as corrosion inhibitors for the AA2024-T3 alloy. The efficiency of such CPs as inhibitors has been tested considering different surface pre-treatments. It should be noted that, although PAni and PEDOT have been successfully used to improve the resistance against corrosion of other metallic substrates, as different types of steel [811], their effects have not been previously reported for aluminum.

\section{EXPERIMENTAL SECTION}

\subsection{Reagents}

Aniline and 3,4-ethylenedioxythiophene (EDOT) monomers, $p$-toluensulphonic acid, sodium chloride, anhydrous lithium perchlorate, tetrabutylamonihexafluorophosphate $\left(\mathrm{TBAPF}_{6}\right)$ and acetonitrile were purchased from Aldrich and used as received. Lithium perchlorate and $\mathrm{TBAPF}_{6}$ (analytical reagent grade) were stored in an oven at $80^{\circ} \mathrm{C}$ before the use in electrochemical trials. Nitric acid and sodium hydroxide, octanethiol and dodecanethiol $\left(\mathrm{C}_{8} \mathrm{SH}, \mathrm{C}_{12} \mathrm{SH}\right)$ were of the analytical reagent grade and used as supplied, as well as Novaclean ${ }^{\circledR}$ AL86LF.

\subsection{Surface Pretreatment}

Chemical pickling was performed by using three different compounds. More specifically, nitric acid and sodium hydroxide solutions were used for acid and basic pickling respectively, whereas Novaclean ${ }^{\circledR}$ was tested as an industrial alternative usually applied to aluminum before anodization and painting processes. In this work Novaclean ${ }^{\circledR}$ was used to improve the adherence between PAni and the aluminum substrate. Typically, the composition of Novaclean ${ }^{\circledR}$ includes phosphoric acid (20-50\%), $\mathrm{C}_{8}-\mathrm{C}_{10}$ alcohols with polyethylenglicol and polypropylenglicolmonobenzyleter $(2-10 \%)$, and $N, N^{\prime}$ diethylthiourea $(0.1-1 \%)$. The operational conditions used for this pre-treatment (i.e. concentration and time) are described in the Results and Discussion section.

For coating with PAni the surface pre-treatment was restricted to chemical pickling while for coating with PEDOT the chemical pickling treatment was completed with the incorporation of alkanethiol selfassembled monolayers (SAMs). More specifically, SAMs of octanethiol or dodecanethiol (Scheme 1) were deposited on the aluminum surface after the Novaclean ${ }^{\circledR}$ pre-treatment and before the polymerization process.

\subsection{Synthesis of PAni and PEDOT}

Aniline and EDOT polymerizations were carried out using a VersaStat II potentiostat-galvanostat connected to a computer controlled through a Power Suite Princenton Applied Research program. Experiments were conducted in a standard three-electrode twocompartment cell under nitrogen atmosphere (99.995\% purity) at $25^{\circ} \mathrm{C}$. After electropolymerization, all PAni- and PEDOT-coated electrodes were 
cleaned with $p$-toluensulphonic acid and acetonitrile, respectively, and dried with nitrogen.

The polymerization of aniline was performed using $p$-toluensulphonic acid as supporting electrolyte, while two different supporting electrolytes, $\mathrm{TBAPF}_{6}$ and $\mathrm{LiClO}_{4}$, were considered for the polymerization of EDOT. The two CPs were synthesized by chronoamperometry (CA) under a constant potential, which was 1.50 and $1.40 \mathrm{~V}$ for PAni and PEDOT, respectively.

For the polymerization of PAni the cathodic compartment of the cell was filled with $40 \mathrm{~mL}$ of a $0.17 \mathrm{M}$ aniline aqueous solution containing $1 \mathrm{M}$ of $p$-toluensulphonic acid while for PEDOT, the anodic compartment was filled with $40 \mathrm{~mL}$ of a $0.1 \mathrm{M}$ monomer solution in acetonitrile with $0.1 \mathrm{M}$ of supporting electrolyte. For both polymers, a volume of $10 \mathrm{~mL}$ of an electrolyte solution was placed in the cathodic compartment.

The AA2024-T3 sheets of $1 \times 1$ or $5 \times 1 \mathrm{~cm}^{2}$ were employed as working electrodes, while the counter electrode was a panel of AA2024-T3 of $1 \times 1 \mathrm{~cm}^{2}$ in all cases. The reference electrode was an $\mathrm{Ag} \mid \mathrm{AgCl}$ electrode containing a $\mathrm{KCl}$ saturated aqueous solution $\left(E^{0} 7=0.222 \mathrm{~V}\right.$ at $25^{\circ} \mathrm{C}$ ), which was connected to the working compartment through a salt bridge containing the electrolyte solution. Before the anodic polymerization process, the aluminum electrodes were pretreated as is described in subsection 2.2.

\subsection{Profilometry, Fourier-Transform Infrared Spectroscopy and UV-Visible Spectroscopy}

The roughness of the samples was determined by profilometry using mechanical profilometer Veeco Dektak 150. The Fourier-transform infrared spectroscopy (FTIR) spectra were recorded using a Nicolet 6700 spectrometer equipped with a Smart SAGA (specular aperture grazing angle) accessory and Omnic software. Films were directly deposited on the aluminum surface. Spectra were collected with an incidence angle of $80^{\circ}$ from the normal surface using a wavenumber range of $4000-600 \mathrm{~cm}^{-1}$ at a resolution of $8 \mathrm{~cm}^{-1}$. The UV-visible spectroscopy spectra were registered using a UV-Vis-NIR Shimadzu UV-3600 spectrophotometer incorporating the software UVProbe v.2.31.

\subsection{Optical and Electron Scanning Microscopy}

Optical micrographs were obtained using an Olympus $\mathrm{BX}-51$ light polarizing microscope opera-ting in a reflection mode with an Olympus $\mathrm{C} 3030 \mathrm{Z}$ digital camera coupled. Detailed studies of the selected samples were carried out by the scanning electron microscopy (SEM) using a Focused Ion Beam Zeiss Neon40 scanning electron microscope equipped with an energy dispersive $\mathrm{X}$-ray (EDX) spectroscopy system and operating at $30 \mathrm{kV}$. The samples were mounted on a double-sided adhesive carbon disc and sputtercoated with a thin layer of carbon to prevent sample charging problems.

\subsection{Accelerated Corrosion Tests}

Accelerated corrosion tests were performed to evaluate the changes at the surface of the coated AA2024T3 pieces vs time in the presence of aggressive environments. More specifically, the behavior of aluminum panels with different pre-treatment and $\mathrm{CP}$ coatings have been systematically compared in two different aggressive media. These studies were carried out using home-made equipment developed and patented in our laboratory [12] for cyclic tests in an aggressive solution. The media considered in this study were: (i) an aqueous solution of sodium chloride (3.5 wt. \%, $\mathrm{pH}=6.6$ ) simulating marine environment; and (ii) an aqueous solution of sodium hydrogen sulfite ( $3.5 \mathrm{wt} . \%, \mathrm{pH}=3.0$ ) simula-ting an urban environment. Both solutions were stored in a polypropylene container with capacity for $30 \mathrm{~L}$ at room temperature. The operating controlled program conditions for one cycle were:

a) Immersion of coated aluminum panels (15 $\mathrm{min}$ )

b) Wring out (30 min)

c) Drying stage with bulbs ( $230 \mathrm{~V}-100 \mathrm{~W}, 10 \mathrm{~min}$ )

d) Cooling time at room temperature $(5 \mathrm{~min})$

In step (a) the specimens were totally immersed into the solution, whereas in step (c) the drying was forced by means of two lamps that provided a temperature similar to the environmental one in field tests $(\sim$ $40^{\circ} \mathrm{C}$ ). The temperature and the relative humidity in the laboratory remained constant at $20^{\circ} \mathrm{C}$ and $50 \%$, respectively, whereas the temperature of the immersion container was $30^{\circ} \mathrm{C}$.

The coated panels were sealed on the edges and around the hole used for securing the pieces. The samples were scribed and extracted from the corrosion medium after an exposure time of 7 days (corresponding to 168 cycles of $1 \mathrm{~h}$ each one) and 14 days (corresponding to 336 cycles of $1 \mathrm{~h}$ each one). All assays were run in triplicate (i.e. considering 3 specimens for each sample and extraction).

\subsection{Electrochemical Polarization Tests}

Electrochemical polarization measurements enable the evaluation of the corrosion behavior of metallic materials faster than accelerated and field corrosion tests. In this work polarization curves were registered by the "intersection method", which derives the corrosion potential and the corrosion rate from the intersection of tangents straight lines to cathodic and anodic polarization curves traced at a higher current density. Both anodic and cathodic polarization curves were registered using an Autolab 


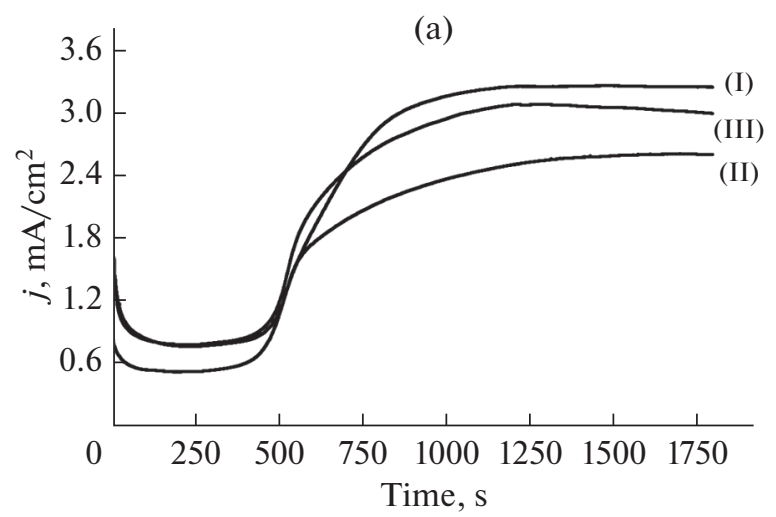

(b)

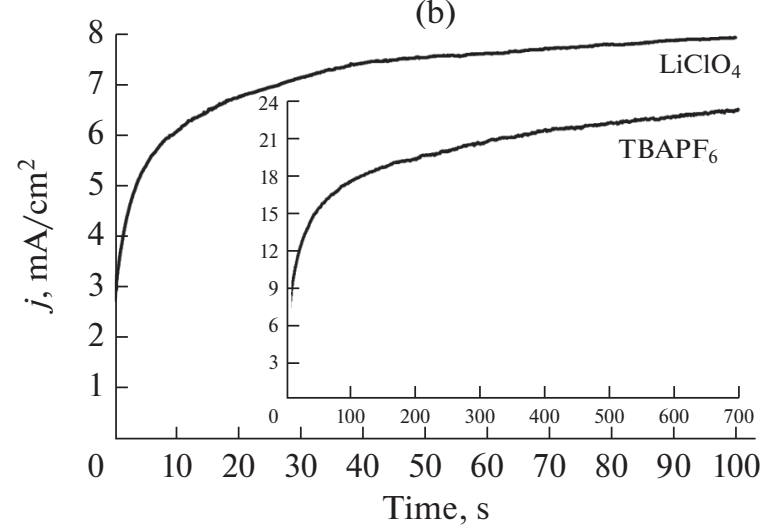

(c)

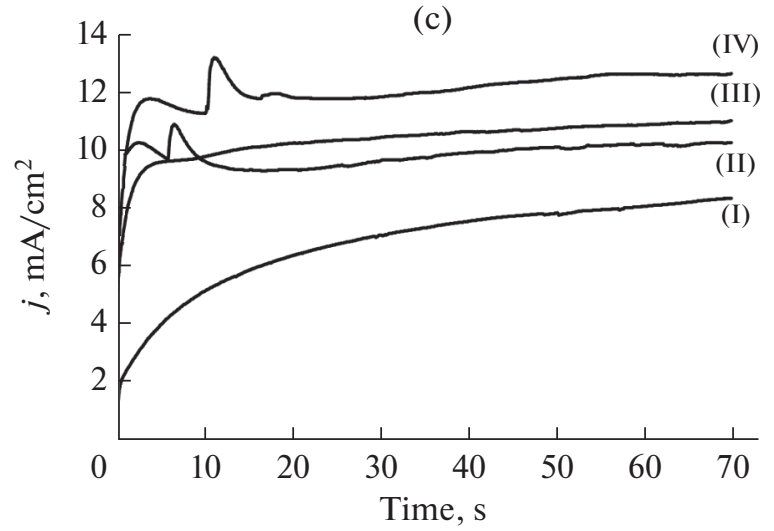

Fig. 1. Chronoamperograms obtained for the oxidation of a $0.17 \mathrm{M}$ aniline aqueous solution with $0.1 \mathrm{M} p$-toluensulphonic acid (a), 0.3 M EDOT solution in acetonitrile with $0.1 \mathrm{M} \mathrm{LiClO}_{4}(\mathrm{~b}, \mathrm{c})$ on a $1 \times 1 \mathrm{~cm}^{2}$ aluminum electrode.

potentiostat-galvanostat equipment connected to the software GPES v4.9 (General Purpose Electrochemical System).

In addition to linear polarization resistance curves, also named Stern-Geary, have been also obtained to allow faster corrosion rate measurements [13, 14]. Those curves were registered using a Versastat II potentiostat-galvanostat equipment connected to the software Electrochemistry PowerSuite v.2.5.

\section{RESULTS AND DISCUSSION}

\subsection{Synthesis and Pretreatment}

Figure 1a shows the chronoamperograms obtained for the oxidation of a $0.17 \mathrm{M}$ aniline aqueous solution with $1 \mathrm{M}$ of $p$-toluensulphonic acid on aluminum electrodes using different electrode pre-treatments. As it can be seen, the current intensity stabilizes after 1000-1200 s. These results were used to define the conditions employed for the preparation of different PAni-coated aluminum samples examined in this work. More specifically, 600, 1200 and 2000 s were the polymerization times $(\theta)$ considered for the preparation of PAni films which were deposited onto aluminum panels without surface pre-treatment $(\mathrm{M}=0)$ and on those pre-treated with 60 or $80 \mathrm{~g} / \mathrm{L}$ Novaclean ${ }^{\circledR}(M=60$ or 80 , respectively) during $8 \mathrm{~min}$. The nomenclature used for these samples consists of PAni M/O: e.g. PAni 0/1200 and PAni 80/1200 refer to PAni films obtained using a polymerization time of $1200 \mathrm{~s}$ and deposited onto aluminum without pre-treatment and onto that pre-treated using $80 \mathrm{~g} / \mathrm{L}$ Novaclean ${ }^{\circledR}$ during $8 \mathrm{~min}$, respectively.

The polymerization conditions of PEDOT were also determined by chronoamperometry (Fig. 1b). Films obtained using $\mathrm{LiClO}_{4}$ and $\mathrm{TBAPF}_{6}$ as supporting electrolyte were generated using a polymerization time $\theta=70$ and $600 \mathrm{~s}$, respectively. Polymer films obtained using $\mathrm{TBAPF}_{6}$ exhibited many irregularities and lumps on the surface, the adherence the aluminum substrate being poor. Chronoamperograms recorded for the oxidation of EDOT using $\mathrm{LiClO}_{4}$ as supporting electrolyte using aluminum substrates pre-treated with Novaclean ${ }^{\circledR}$ under different conditions (Fig. 1c) showed high current density peaks at short times when the pre-treatment time was $8 \mathrm{~min}$. In order to avoid this undesirable effect, the pre-treatment conditions were fixed at $60 \mathrm{~g} / \mathrm{L}$ Novaclean ${ }^{\circledR}$ during 6 min.

\subsection{Surface Characterization}

The arithmetic average roughness ( $\mathrm{Ra}$ ) and thickness $(L)$ of PAni and PEDOT films deposited onto non-treated and pre-treated aluminum substrates were determined by profilometry. Representative cross sectional profiles for PAni $\mathrm{M} / \theta$ films with $\mathrm{M}=60$ and $80 \mathrm{~g} / \mathrm{L}$ Novaclean ${ }^{\circledR}$ and $\theta=600$ and $1200 \mathrm{~s}$ are displayed in Fig. 2a, whereas both $\mathrm{Ra}$ and $L$ values are listed in Table 1 . As it was expected, $\mathrm{Ra}$ and $L$ increase with the polymerization time, independently of $M$, while $\mathrm{Ra}$ is considerably higher for PAni films obtained using the lowest $M$ value, independently of $\theta$. Accordingly, the physical characteristics of aluminum pre-treated with less aggressive conditions promote the growing of polymer chains. It should be remarked that, unfortunately, PAni 0/600 and PAni 0/1200 films were not homogeneous, therefore the surface of non- 
(a)

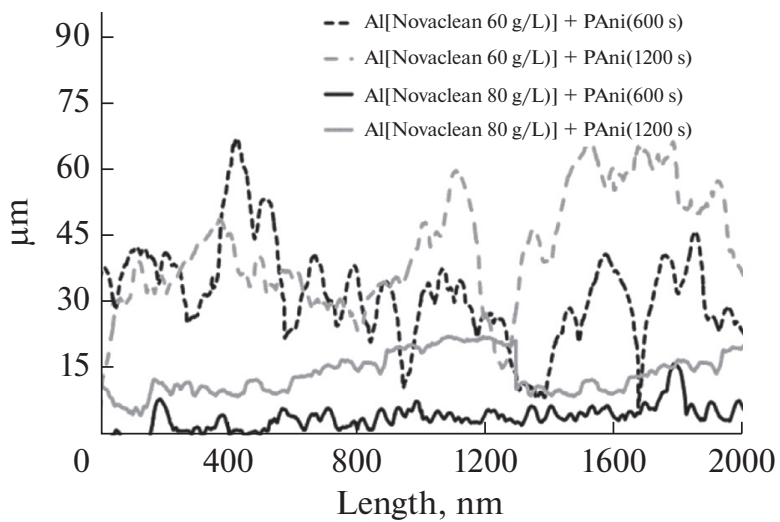

(b)

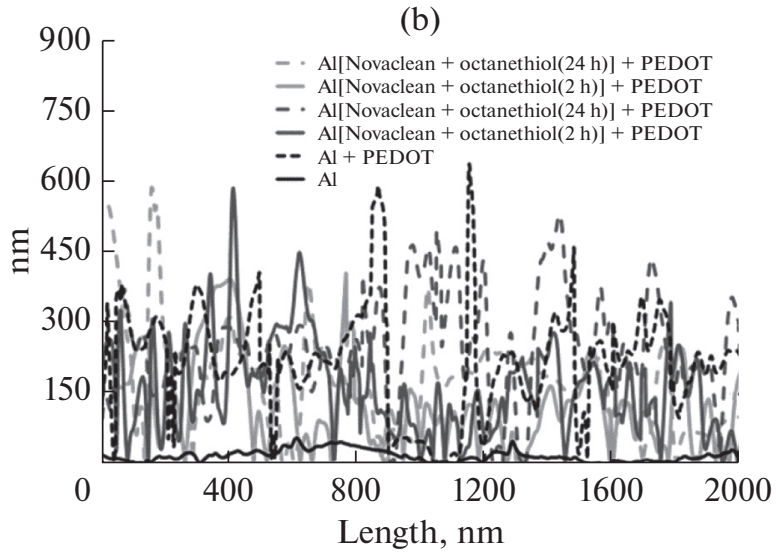

Fig. 2. Cross sectional profiles as obtained by profilometry of (a) Al treated with Novoclean ${ }^{\circledR}(60$ or $80 \mathrm{~g} / \mathrm{L})$ during 8 min and coated by PAni generated electrochemically $(\theta=600$ or $1200 \mathrm{~s})$; and (b) non-treated $\mathrm{Al}$, bare and coated with PEDOT $(\theta=70 \mathrm{~s})$, and Al treated using Novaclean ${ }^{\circledR} 60 \mathrm{~g} / \mathrm{L}$ during $6 \mathrm{~min}$ with subsequent incorporation of alkanethiol and coated with PEDOT $(\theta=70 \mathrm{~s})$.

treated aluminum remaining partially uncoated after a polymerization time of $1200 \mathrm{~s}$.

Figure $2 \mathrm{~b}$ compares representative cross-sectional profiles registered for the following systems: (1) non- treated bare aluminum; (2) non-treated aluminum coated with PEDOT; and (3) aluminum treated with Novaclean ${ }^{\circledR} 60 \mathrm{~g} / \mathrm{L}$ during $6 \mathrm{~min}$, subsequent incorporation of octanethiol or dodecanethiol SAMs and final coating with PEDOT. In all cases PEDOT films were prepared using $\mathrm{LiClO}_{4}$ as supporting electrolyte and a polymerization time $\theta=70 \mathrm{~s}$, while the incorporation of alkanethiol SAMs was carried out considering two different incubation periods: $2 \mathrm{~h}$ or $24 \mathrm{~h}$ (Scheme 1 above). The $\mathrm{Ra}$ and $L$ values determined for all these systems are listed in Table 1. It is worth noting that the surface roughness of PEDOT films electrochemically deposited onto aluminum is higher than that obtained for the same polymer on stainless steel as substrate [15], this observation being independent of the application of any surface pre-treatment or without that. Thus, in a recent study about the polymerization of PEDOT onto steel AISI 316L using experimental conditions identical to those of this work, we observed that roughness grows with the polymerization time $\theta$ as follows: $\mathrm{Ra}=0.9 \cdot \theta+68.4$ [15]. Accordingly, the roughness of PEDOT films deposited onto steel is expected to be $\sim 131 \mathrm{~nm}$ for a polymerization time $\theta=70 \mathrm{~s}$.

Comparison of the results obtained considering different pre-treatments indicates the surface becomes flatter when the alkanethiol SAMs are incorporated using the shortest incubation time $(2 \mathrm{~h})$. Thus, the Ra values obtained for SAMs formed using the latter incubation time are around $25-30 \%$ lower than those achieved using an incubation time of $24 \mathrm{~h}$. Moreover, the Ra value increases with the length of the alkyl group in the alkanethiol, independently of the incubation time. On the other hand, it is worth noting that the polymerization conditions required for the formation of homogeneous PAni and PEDOT films completely coating the surface of pre-treated aluminum are very different and, therefore, Ra and $L$ values cannot be compared. Thus, the thickness of PAni- and PEDOT-coatings corresponds to different

Table 1. Arithmetic average roughness $(\mathrm{Ra})$ of bare and coated aluminum surfaces and thickness $(L)$ of electrochemically deposited organic coatings

\begin{tabular}{|c|c|c|}
\hline Surface & $\mathrm{Ra}$ & $L, \mu \mathrm{m}$ \\
\hline Bare aluminum & $22 \mathrm{~nm}$ & \\
\hline Aluminum treated with $60 \mathrm{~g} / \mathrm{L}$ Novaclean ${ }^{\circledR}$ during $8 \mathrm{~min}$ and coated with PAni $(\theta=600 \mathrm{~s})$ & $33 \mu \mathrm{m}$ & 70 \\
\hline Aluminum treated with $60 \mathrm{~g} / \mathrm{L}$ Novaclean ${ }^{\circledR}$ during $8 \mathrm{~min}$ and coated with PAni $(\theta=1200 \mathrm{~s})$ & $43 \mu \mathrm{m}$ & 159 \\
\hline Aluminum treated with $80 \mathrm{~g} / \mathrm{L}$ Novaclean ${ }^{\circledR}$ during $8 \mathrm{~min}$ and coated with PAni $(\theta=600 \mathrm{~s})$ & $5 \mu \mathrm{m}$ & 64 \\
\hline Aluminum treated with $80 \mathrm{~g} / \mathrm{L}$ Novaclean ${ }^{\circledR}$ during $8 \mathrm{~min}$ and coated with PAni $(\theta=1200 \mathrm{~s})$ & $16 \mu \mathrm{m}$ & 150 \\
\hline Aluminum coated with PEDOT & $246 \mathrm{~nm}$ & 0.10 \\
\hline $\begin{array}{l}\text { Aluminum with surface pre-treatment (Novaclean }{ }^{\circledR} \text { during } 6 \text { min }+ \text { octanethiol } 2 \mathrm{~h} \text { ) and } \\
\text { coated with PEDOT }\end{array}$ & $162 \mathrm{~nm}$ & 0.12 \\
\hline $\begin{array}{l}\text { Aluminum with surface pre-treatment }\left(\text { Novaclean }{ }^{\circledR} \text { during } 6 \text { min }+ \text { octanethiol } 24 \mathrm{~h}\right) \text { and } \\
\text { coated with PEDOT }\end{array}$ & $212 \mathrm{~nm}$ & 0.14 \\
\hline $\begin{array}{l}\text { Aluminum with surface pre-treatment (Novaclean }{ }^{\circledR} \text { during } 6 \text { min }+ \text { dodecanethiol } 2 \mathrm{~h} \text { ) and } \\
\text { coated with PEDOT }\end{array}$ & $190 \mathrm{~nm}$ & 0.11 \\
\hline $\begin{array}{l}\text { Aluminum with surface pre-treatment (Novaclean }{ }^{\circledR} \text { during } 6 \text { min }+ \text { dodecanethiol } 24 \text { h) } \\
\text { and coated with PEDOT }\end{array}$ & $273 \mathrm{~nm}$ & 0.12 \\
\hline
\end{tabular}



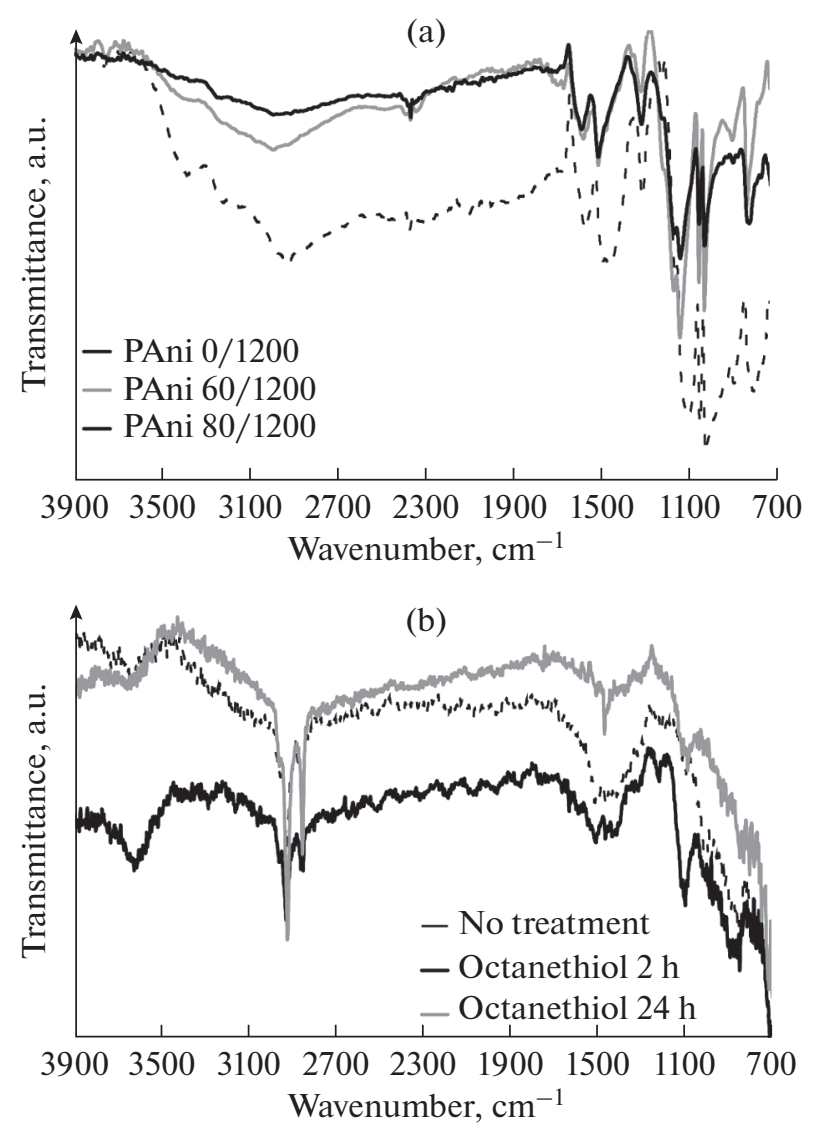

Fig. 3. FTIR spectra of: (a) PAni $M / 1200$ films with $M=$ 0,60 and $80 \mathrm{~g} / \mathrm{L}$ Nocaclean ${ }^{\circledR}$; (b) PEDOT films deposited onto $\mathrm{Al}$ untreated and treated with $60 \mathrm{~g} / \mathrm{L}$ Novaclean ${ }^{\circledR}$ and subsequent immersion in octanethiol for $2 \mathrm{~h}$ and $24 \mathrm{~h}$.

length scales: micrometric $(60-160 \mu \mathrm{m}) v s$ nanometric $(\sim 100 \mathrm{~nm})$.

Figure 3a compares representative FTIR spectra recorded for PAni M/1200 with $\mathrm{M}=0,60$ and $80 \mathrm{~g} / \mathrm{L}$ Novaclean ${ }^{\circledR}$. Characteristics bands typically associated to PAni functional groups are clearly detected [16]. The peaks located around $770-880 \mathrm{~cm}^{-1}$ have been attributed to ring $\mathrm{C}-\mathrm{H}$ deformations, while those at $3000 \mathrm{~cm}^{-1}$ and $3200 \mathrm{~cm}^{-1}$ are associated with aromatic $\mathrm{C}-\mathrm{H}$ bond and $\mathrm{N}-\mathrm{H}$ bond stretching, respectively. Other characteristic peaks are those at 1300 and $1500 \mathrm{~cm}^{-1}$, which corresponds to $\mathrm{C}-\mathrm{N}$ bond and the aromatic ring stretching, respectively. Finally,

a sharp band at $1000-1100 \mathrm{~cm}^{-1}$ is due to $\mathrm{SO}_{3}^{-}$of the $p$-toluensulphonic acid dopant agent.

The FTIR spectra of PEDOT, deposited onto untreated aluminum and that treated with $60 \mathrm{~g} / \mathrm{L}$ Novaclean ${ }^{\circledR}$ with subsequent immersion in octanethiol for $2 \mathrm{~h}$ and $24 \mathrm{~h}$, are compared in Figure $3 \mathrm{~b}$. The characteristic stretching bands at 2850 and $2918 \mathrm{~cm}^{-1}$, correspond to the $\mathrm{C}-\mathrm{H}$ and $\mathrm{S}-\mathrm{H}$ bonds, respectively. Furthermore, the $\mathrm{C}=\mathrm{C}\left(1400-1600 \mathrm{~cm}^{-1}\right), \mathrm{C}-\mathrm{C}$
(700-780 and $\left.1000-1460 \mathrm{~cm}^{-1}\right), \mathrm{C}-\mathrm{O}-\mathrm{C}(1080-$ $\left.1240 \mathrm{~cm}^{-1}\right)$ and $\mathrm{C}-\mathrm{S}-\mathrm{C}\left(970-1000 \mathrm{~cm}^{-1}\right)$ are also identified from the spectra.

\subsection{Morphologic Analysis}

Figure 4a displays the surface morphology of bare AA2024-T3 before any treatment. Surface imperfections are due to the existence of precipitates with variable composition: i.e. $\mathrm{Cu}, \mathrm{Mg}, \mathrm{Si}, \mathrm{Mn}$ and $\mathrm{Fe}$. The composition of bare aluminum substrates, as determined by the EDX, is compared with that of the standard alloy in Table 2.

The morphology of untreated aluminum coated with PAni $(\theta=1200 \mathrm{~s})$ and PEDOT $(\theta=70 \mathrm{~s})$ is displayed in Fig. 4b,c, respectively. As it can be seen, the morphology of the two coatings is completely different. More specifically, PAni exhibits a smooth and compact texture with some superficial irregularities, whereas PEDOT forms small clusters that aggregate at a given place, a very irregular and porous film.

Representative SEM micrographs of aluminum treated with $60 \mathrm{~g} / \mathrm{L}$ Novaclean ${ }^{\circledR}$ during 6 min are displayed in Fig. 4d. As can be seen, Novaclean ${ }^{\circledR}$ causes the appearance of numerous pinholes and small cracks in the metal surface, evidencing that it is an aggressive treatment. In spite of this, the physical characteristics of the treated surfaces may improve the adherence of the coating (see next sub-section). As it is reflected in Fig. 4e for PAni 60/1200, the morphology of PAni deposited onto treated substrates is similar to that observed for the polymer electrogenerated onto untreated aluminum (Fig. 4b). Likewise, the morphology of PEDOT coatings electrochemically polymerized onto alkanethiol SAMs covering the treated aluminum was very similar to that displayed in Fig. 4c. This feature, which is independent of the chemical nature of both the length of the alkyl group in alkanethiol and the incubation time used for the incorporation of the SAM, is evidenced in Figure $4 \mathrm{f}$ that compares the morphology of PEDOT deposited onto octanethiol and dodecanethiol SAMs using incubation times of $24 \mathrm{~h}$ and $2 \mathrm{~h}$, respectively.

\subsection{Corrosion Protection}

Corrosion accelerated tests were carried out considering four specimens for each of the following PAni-coatings: PAni 0/1200, PAni 60/1200 and PAni $80 / 1200$. All specimens were protected at the edges with an impermeable adhesive-type epoxy resin. Once the accelerated corrosion cycles started, one specimen of each sample was extracted after one and two weeks, which correspond to 168 and 336, cycles, respectively. It should be emphasized that this is a very aggressive assay, in which specimens spent half time of the cycle when immersed into the corrosion medium. Two different corrosion media were employed: a 3.5\% 

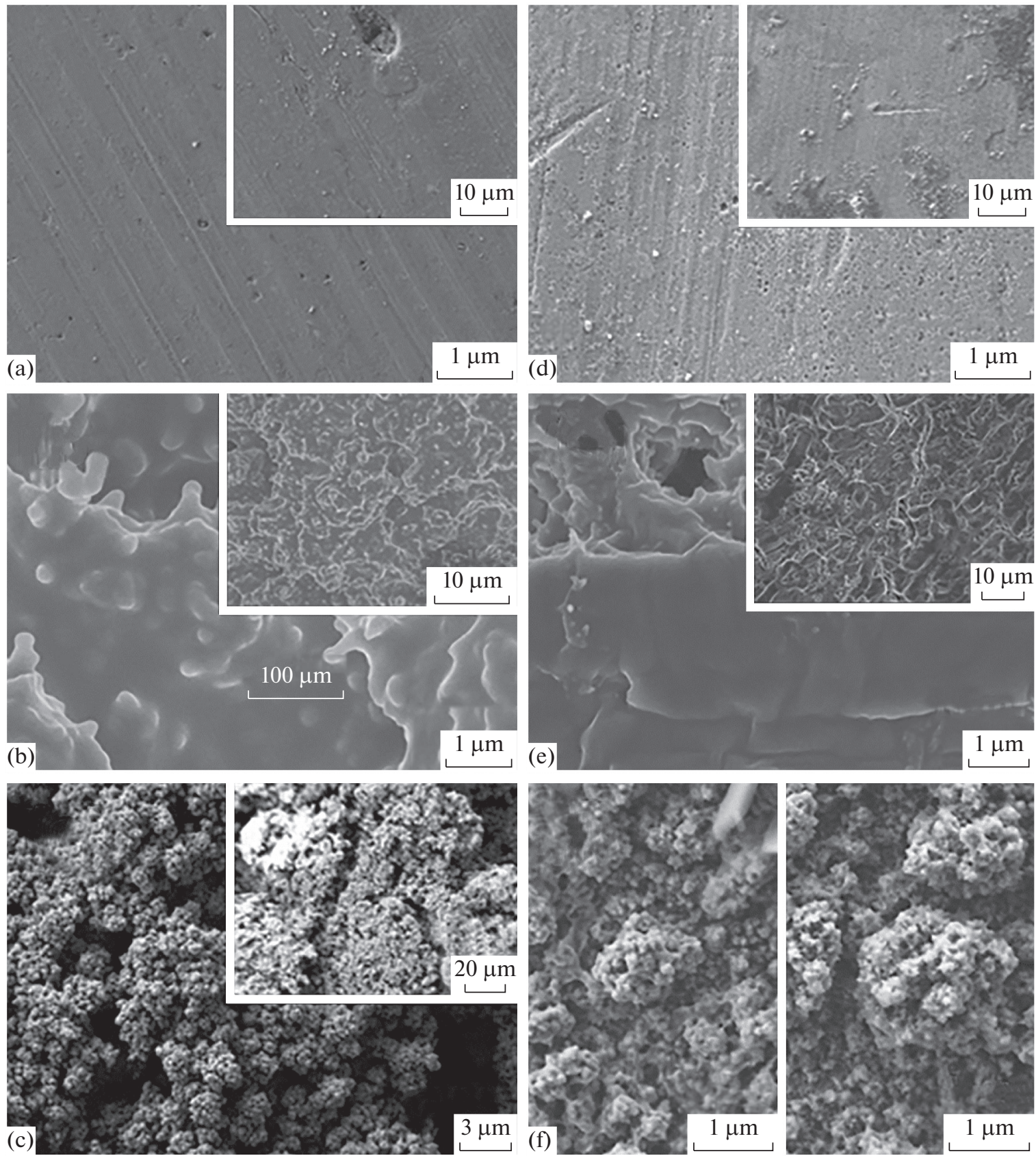

Fig. 4. SEM micrographs of: (a) non-treated AA2024-T3; (b) PAni 0/1200; (c) PEDOT deposited onto non-treated AA2024-T3; (d) AA2024-T3 treated with $60 \mathrm{~g} / \mathrm{L}$ Novaclean ${ }^{\circledR}$ during $6 \mathrm{~min}$; (e) PAni 60/1200; and (f) PEDOT deposited onto the alkanethiol SAM coating the pre-treated Al: octanethiol (left) and dodecanethiol (right) SAM obtained with incubation time $24 \mathrm{~h}$ and $2 \mathrm{~h}$, respectively.

sodium chloride solution $(\mathrm{pH}=6.6)$ and a sodium hydrogen sulfite solution $(3.5 \mathrm{wt} . \%, \mathrm{pH}=3.0)$

As the behaviors observed in sodium chloride and sodium hydrogen sulfite were very similar for PAni
0/1200, PAni 60/1200 and PAni 80/1200, the discussion has been focused on the former corrosion medium. Figure 5 displays photographs of the representative initial specimens and the specimens

Table 2. Composition of AA2024-T3 determined in this work by EDX and the standard one

\begin{tabular}{l|c|c|c|c|c|c}
\hline & $\mathrm{Al}$ & $\mathrm{Cu}$ & $\mathrm{Mg}$ & $\mathrm{Mn}$ & $\mathrm{Si}$ & $\mathrm{Fe}$ \\
\hline This work & $93.1 \pm 1.7$ & $4.5 \pm 0.9$ & $1.6 \pm 0.9$ & $0.5 \pm 0.1$ & $<0.1$ & $<0.1$ \\
Standard & $90.7-94.7$ & $3.8-4.9$ & $1.2-1.8$ & $0.3-0.9$ & Max. 0.5 & Max. 0.5 \\
\hline
\end{tabular}

SURFACE ENGINEERING AND APPLIED ELECTROCHEMISTRY $\quad$ Vol. $54 \quad$ No. $3 \quad 2018$ 
Table 3. Electrochemical parameters from polarization and linear polarization assays for most representative PAni- and PEDOT-based coatings

\begin{tabular}{l|c|c|l|c|c}
\hline \multicolumn{1}{c|}{ Specimen } & $E_{\text {corr }}, \mathrm{V}$ & $R_{\mathrm{p}}, \Omega / \mathrm{cm}^{2}$ & Specimen & $E_{\mathrm{corr}}, \mathrm{V}$ & $R_{\mathrm{p}}, \Omega / \mathrm{cm}^{2}$ \\
\hline Bare AA2024-T3 & -0.551 & 1320 & & & \\
PAni-based coatings & & & PEDOT-based coatings & & \\
PAni 0 /1200 & -0.545 & 1816 & PEDOT & -0.616 & 1050 \\
PAni 60 /1200 & -0.537 & 2565 & PEDOT+octanethiol (24h) & -0.609 & 1120 \\
PAni 80/1200 & -0.582 & 2940 & PEDOT+dodecane thiol (24h) & -0.553 & 1210 \\
\hline
\end{tabular}

extracted after 1 and 2 weeks. As it can be seen, samples present blistering in different zones of the surfaces and solid depositions of salt from the sodium chloride

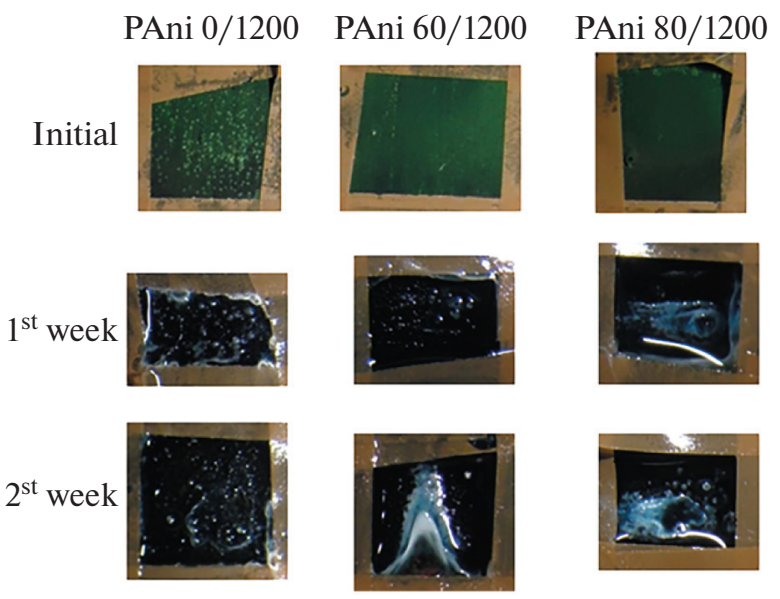

Fig. 5. Micrographs of representative specimens of untreated and treated AA2024-T3 coated with PAni: before (initial) and after (extraction after 1 and 2 weeks) accelerated corrosion assays in sodium chloride.

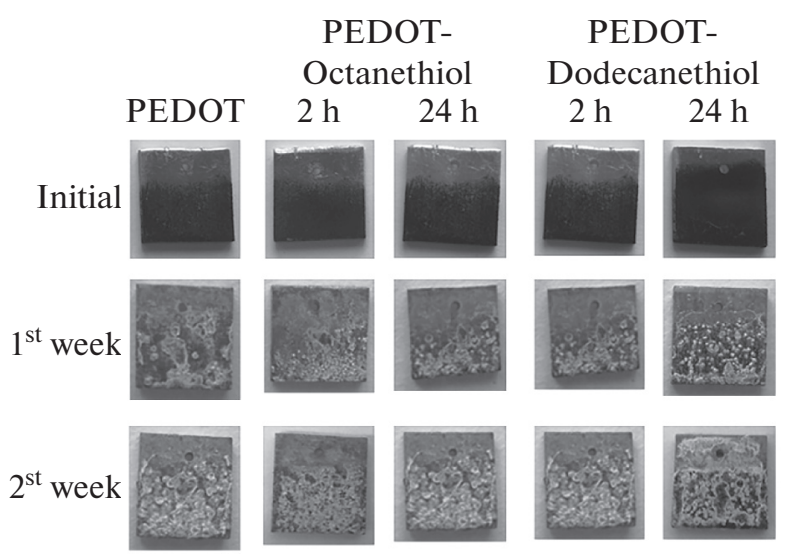

Fig. 6. Micrographs of representative specimens of untreated and treated AA2024-T3 coated with PEDOT: before (initial) and after (extraction after 1 and 2 weeks) accelerated corrosion assays in sodium chloride. solution, which were particularly pronounced after 2 weeks. Amazingly, the best results were obtained for PAni 0/1200, indicating that the PAni adhesion onto the aluminum surface becomes significantly worse after the pre-treatment.

Figure 6 displays photographs of both untreated and treated PEDOT-coated specimens after 1 and 2 weeks of exposition to the sodium chloride corrosive solution. As it can be seen, results were similar to those obtained for PAni coatings, blistering on the CP and solid depositions of salt similar to those found in PAni being also present. Again these results suggest that CPs do not improve the resistance against corrosion of this aluminum alloy.

Complementary corrosion assays using electrochemical techniques, as classical polarization curves and linear polarization resistance, were use in the present study. The results are displayed in Figs. 7 and 8 for samples coated with PAni and PEDOT, respectively. As it can be seen, the results for the pre-treated samples coated with PAni are similar in all cases. Thus, polarization curves do not exhibit any signs of anodic passivation or cathodic polarization by concentration with the diffusional control (Fig. 7).

The current intensity is around $5 \times 10^{-4} \mathrm{~A}$ and $10^{-5} \mathrm{~A}$ for non-coated aluminum and PAni-coated pretreated samples, respectively, indicating that PAni does not provide any substantial improvement in terms of corrosion protection. Polarization curves are fully consistent with linear polarization results, the main parameters from the corresponding electrochemical analyses (i.e. the corrosion potential and the polarization resistance) being listed in Table 3 .

On the other hand, polarization curves for PEDOT samples in sodium chloride and sodium hydrogen sulfite (Fig. 8) indicate a light displacement of curves to higher corrosion potentials when the CP is applied onto treated surfaces. In spite of this, no significant changes were produced in the current density, being in about $10^{-5} \mathrm{~A} \cdot \mathrm{cm}^{-2}$ in all cases. 


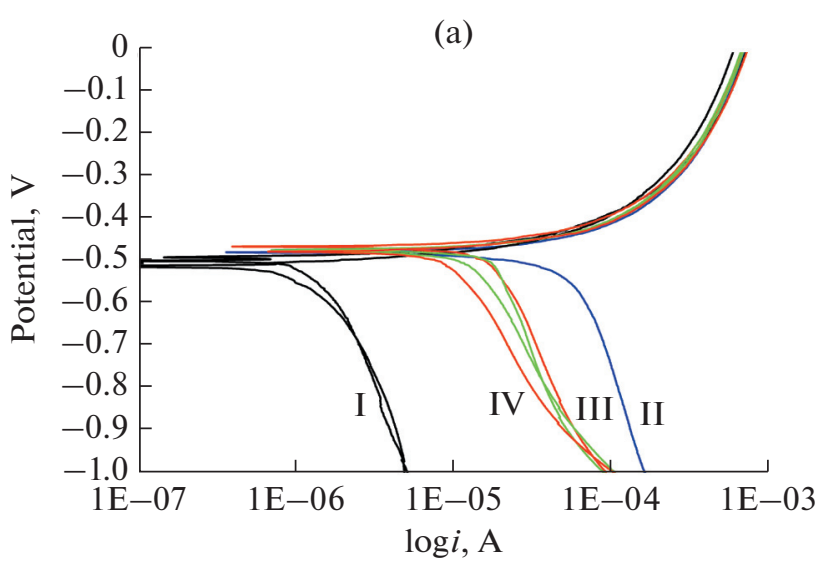

(b)

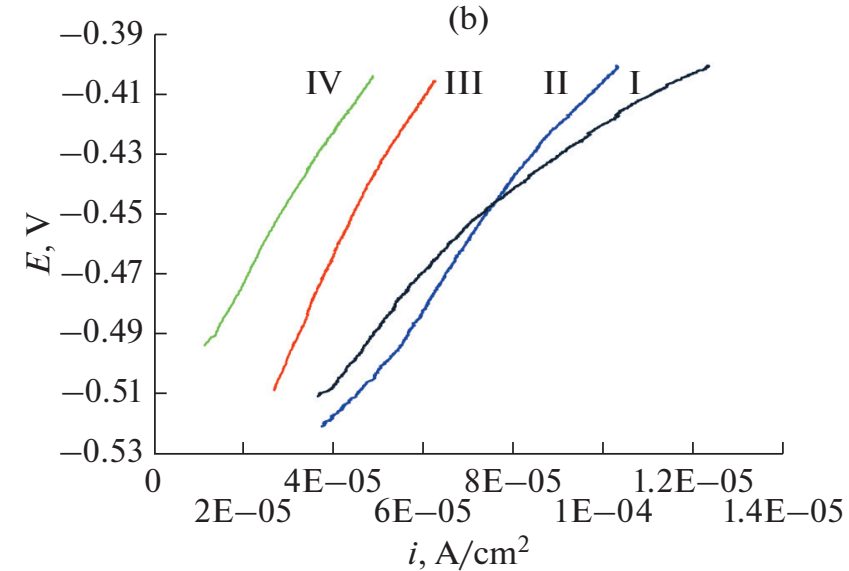

Fig. 7. Electrochemical polarization tests for PAni-based coating in sodium chloride: (a) polarization curves and (b) linear resistance polarization curves. Specimens correspond to: (i) bare aluminum AA2024-T3; (ii) untreated AA2024-T3 coated with PAni (PAni 0/1200); and (iii) and (iv) treated AA2024-T3 coated with PAni (PAni 60/1200 and PAni 80/1200, respectively).

\section{CONCLUSIONS}

The synthesis and electrochemical characterization of PAni and PEDOT have been carried out along with the surface characterization of the mentioned aluminum alloy used as substrate. Additio-nally, the properties of AA2024-T3 coated with two different CPs, PAni and PEDOT, were examined. The coatings were directly obtained on the metal substrate, both untreated and pre-treated by chemical etching (followed by alkanethiol deposition in the case of PEDOT), by electropolymerization of respective monomers. The objective of surface pre-treatments was to improve the adherence of the CPs on the aluminum substrate. After physicochemical and morphological characterization of the coatings, the corrosion protection properties of aluminum coated samples was evaluated using accelerated assays and electrochemical polarization techniques. Electrochemical and corrosion tests applied to aluminum coated with the CPs show a discrete behavior in their application as protective coatings, unlike their excellent behavior for steel alloys
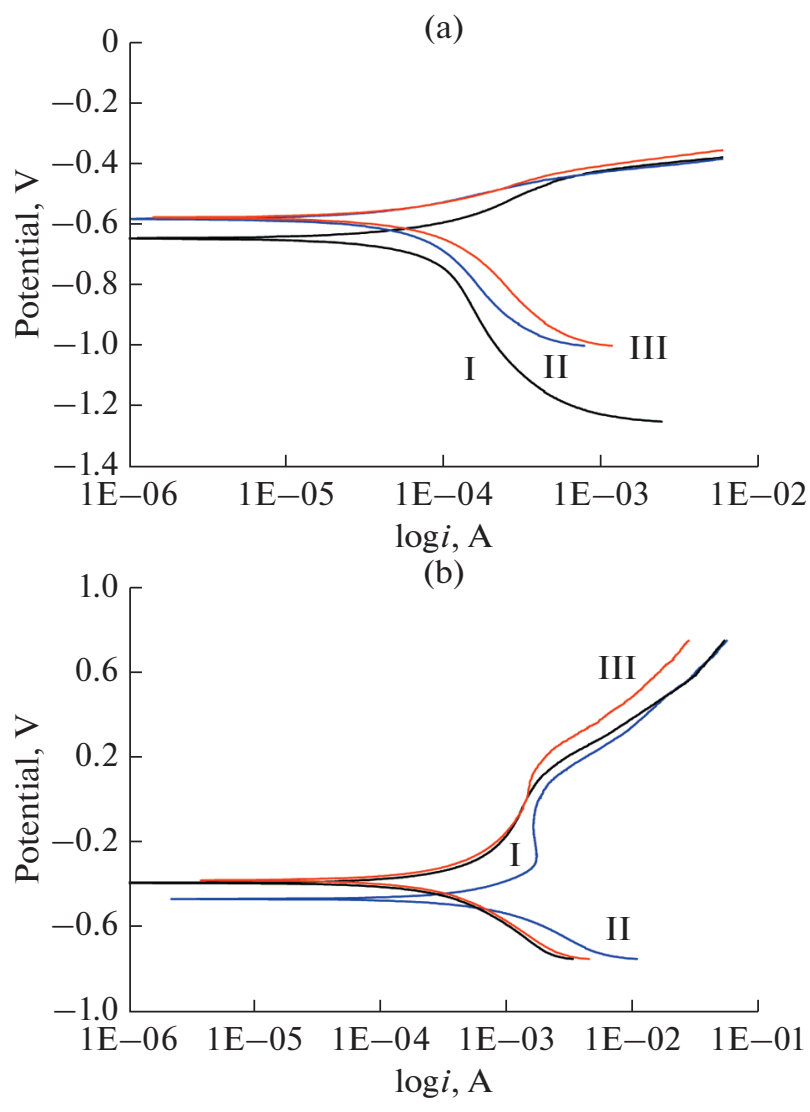

Fig. 8. Polarization curves for PEDOT-based coatings in (a) sodium chloride and (b) sodium hydrogen sulfite: (i) bare AA2024-T3; and treated AA2024-T3 with subsequent incorporation of (ii) octanethiol (24 h) or (iii) dodecanethiol (24 h) SAM.

[17-20]. The corrosion protection does not improve significantly when a CP is deposited on pre-treated aluminum surfaces. These important distinctions arise from different surface characteristics of both metals, aluminum and steel, which induces notable differences in the adherence of the CPs to the substrate.

\section{ACNOWLEDGMENTS}

The authors acknowledge the supports from the Spanish Ministry of Economy, Industry and Competitiveness and the European Fund for Economic and Regional development for the project grant MAT2015-69367-R. Carlos Alemán is grateful for the assistance of research in the framework of the prize "ICREA Academia" for excellence in research funded by the Generalitat de Catalunya.

\section{REFERENCES}

1. Uhlig's Corrosion Handbook, Electrochemical Society Series, New Jersey: Wiley, 2011. 
2. Iannuzi, M. and Frankel, G.S., Corros. Sci., 2007, vol. 49, pp. 2371-2391.

3. Pletcher, D. and Walsh, F.C., Industrial Electrochemistry, New York: Chapman and Hall, 1990.

4. Mourtalier, V., Gigandet, M.P., Ricq, I., and Pagetti, J., Appl. Surf. Sci., 2001, vol. 183, pp. 1-9.

5. Yasakau, K.A., Zheludkevich, M.L., Karavai, O.V., and Ferreira, M.G.S., Prog. Org. Coat., 2008, vol. 3, pp. 352-361.

6. Palanivel, V., Huang, Y., and van Ooij, W.J., Prog. Org. Coat., 2005, vol. 53, p. 153.

7. Zheludkevich, M.L., Yasakau, K.A., Poznyak, S.K., and Ferreira, M.G.S., Corros. Sci., 2005, vol. 47, pp. 3368-3383. https://doi.org/10.1016/j.corsci. 2005.05.040.

8. Armelin, E., Aleman, C., and Iribarren, J.I., Prog. Org. Coat., 2009, vol. 65, pp. 88-93.

9. Zhang, Y., Shao, Y., Liu, X., Shi, C., et al., Prog. Org. Coat., 2017, vol. 111, pp. 240-247.

10. Xu, J., Zhang, Y, Zhang, D, Tang, Y., et al., Prog. Org. Coat., 2015, vol. 88, pp. 84-91.
11. Pagotto, J.F., Recio, F.J., Motheo, A.J., and Herrasti, P., Surf. Coat. Technol., 2016, vol. 289, pp. 23-28.

12. Liesa, F., Alemán, C., and Iribarren, J.I., ES Patent P200502713, 2005.

13. Stansbury, E.E. and Buchanan, R.A., Fundamentals of Electrochemical Corrosion, Materials Park, Oh: ASM Int., 2000.

14. Stern, M. and Geary, A.L., J. Electrochem. Soc., 1957, vol. 104, no. 1, pp. 56-63.

15. Aradilla, D., Estrany, F., Armelin, E. and Alemán, C., Thin Solid Films, 2012, vol. 520, no. 13, pp. 4402-4409.

16. Siva, T., Kamaraj, K., and Sathiyanarayanan, S., Prog. Org. Coat., 2014, vol. 77, pp. 1095-1103.

17. Kalendová, A., Veselý, D., Kohl, M., and Stejskal, J., Prog. Org. Coat., 2015, vol. 78, pp. 1-20.

18. Martí, E.M., Liesa, F., Iribarren, J.I., and Alemán, C., Prog. Org. Coat., 2010, vol. 69, no. 1, pp. 26-30.

19. Sambyal, P., Ruhi, G., Dhawan, R., and Dhawan, S.K., Surf. Coat. Technol., 2016, vol. 303, pp. 362-371.

20. Shanmugham, C. and Rajendran, N., Prog. Org. Coat., 2015, vol. 89, pp. 42-49. 